Sanne Ziethen, Nina Peter (Hg.)

Währung - Krise - Emotion

Edition Kulturwissenschaft | Band 248 
Sanne Ziethen (Dr. phil.), geb. 1977, ist wissenschaftliche Mitarbeiterin am Institut für Geschichte der Stiftung Universität Hildesheim. Als Kulturwissenschaftlerin promovierte sie über deutsch-französische Feindbilder (1807-1930) und forscht und lehrt im Bereich Wirtschaftskrisen und Emotionsgeschichte.

Nina Peter (Dr.), geb. 1985, ist Assistentin am Institut für Germanistik der Universität Bern und promovierte dort mit einer Arbeit über »Poetiken der Ökonomie. Finanzkrisen und Spekulation in der Literatur vom 19. bis zum 21. Jahrhundert«. 
Sanne Ziethen, Nina Peter (Hg.)

\section{Währung - Krise - Emotion}

Kollektive Wahrnehmungsweisen von Wirtschaftskrisen 
Das Symposium hätte nicht ohne finanzielle Unterstützung stattfinden können. Wir danken der Volksbank eG Hildesheim-Lehrte-Pattensen, der Universitätsgesellschaft der Stiftung Universität Hildesheim und dem Institut für Geschichte für die Bereitstellung von Mitteln aus dem Programm Erasmus+ der Europäischen Union.
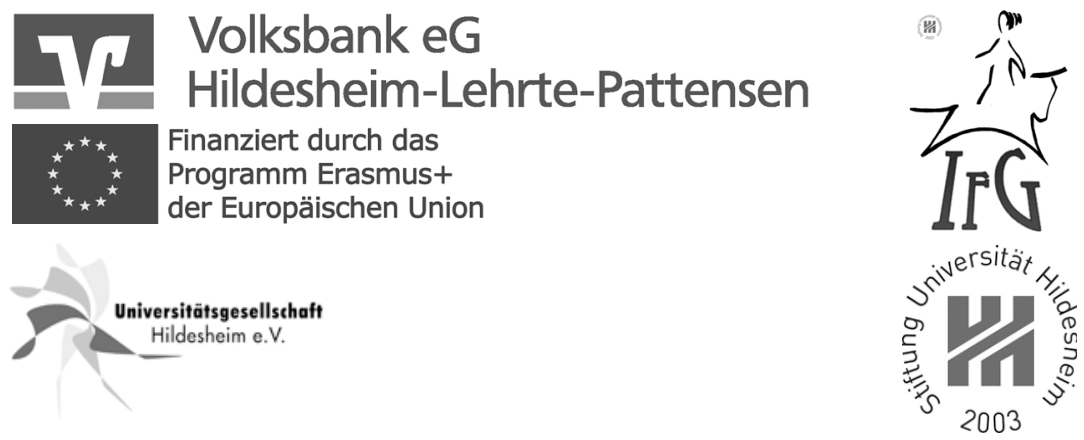

\section{Bibliografische Information der Deutschen Nationalbibliothek}

Die Deutsche Nationalbibliothek verzeichnet diese Publikation in der Deutschen Nationalbibliografie; detaillierte bibliografische Daten sind im Internet über http://dnb.d-nb. de abrufbar.

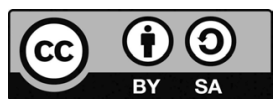

Dieses Werk ist lizenziert unter der Creative Commons Attribution-ShareAlike 4. 0 Lizenz (BY-SA). Diese Lizenz erlaubt unter Voraussetzung der Namensnennung des Urhebers die Bearbeitung, Vervielfältigung und Verbreitung des Materials in jedem Format oder Medium für beliebige Zwecke, auch kommerziell, sofern der neu entstandene Text unter derselben Lizenz wie das Original verbreitet wird. (Lizenz-Text:

https://creativecommons.org/licenses/by-sa/4.o/deed.de)

Die Bedingungen der Creative-Commons-Lizenz gelten nur für Originalmaterial. Die Wiederverwendung von Material aus anderen Quellen (gekennzeichnet mit Quellenangabe) wie z.B. Schaubilder, Abbildungen, Fotos und Textauszüge erfordert ggf. weitere Nutzungsgenehmigungen durch den jeweiligen Rechteinhaber.

\section{Erschienen 2021 im transcript Verlag, Bielefeld ( ) Sanne Ziethen, Nina Peter (Hg.)}

Umschlaggestaltung: Maria Arndt, Bielefeld

Umschlagcredit: Collage unter Verwendung des Bildes: Berlin, Bankenkrach, Andrang bei der Sparkasse, 1932, Bundesarchiv Bild 102-12023, CC BY-SA 3.0 de

Lektorat: Sanne Ziethen und Nina Peter

Druck: Majuskel Medienproduktion GmbH, Wetzlar

Print-ISBN 978-3-8376-5504-9

PDF-ISBN 978-3-8394-5504-3

https://doi.org/10.14361/9783839455043

Gedruckt auf alterungsbeständigem Papier mit chlorfrei gebleichtem Zellstoff. Besuchen Sie uns im Internet: $h t t p s: / / w w w . t r a n s c r i p t-v e r l a g . d e$ Unsere aktuelle Vorschau finden Sie unter www.transcript-verlag.de/vorschau-download 